\title{
Dynamic Price Competition with Capacity Constraints and a Strategic Buyer
}

James Anton

Duke University
Gary Biglaiser

UNC Chapel Hill
Nikolaos Vettas

Athens University of

Economics and Business

September 28, 2012

ERID Working Paper Number 137

This paper can be downloaded without charge from the Social Science Research Network Electronic Paper Collection:

http://ssrn.com/abstract=2170409

\section{Economic Research Initiatives at Duke WORKING PAPERS SERIES

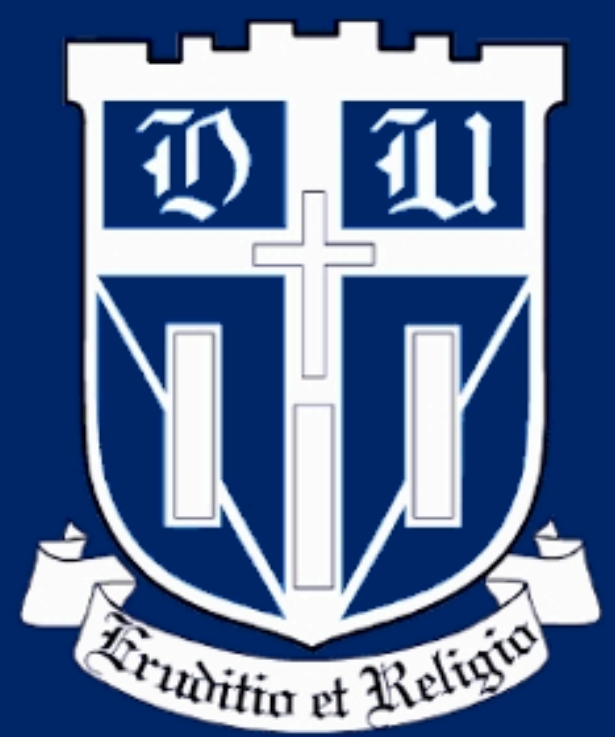




\title{
Dynamic price competition with capacity constraints and a strategic buyer
}

\author{
James J. Anton, Gary Biglaiser, and Nikolaos Vettas ${ }^{1}$
}

28 September, 2012

\footnotetext{
${ }^{1}$ Anton: Fuqua School of Business, Duke University, Durham, NC 27708-0120, USA; e-mail james.anton@duke.edu. Biglaiser: Department of Economics, University of North Carolina, Chapel Hill, NC 27599-3305, USA; e-mail: gbiglais@email.unc.edu. Vettas: Department of Economics, Athens University of Economics and Business, 76 Patission Str., Athens 10434, Greece and CEPR, U.K.; e-mail: nvettas@aueb.gr. We are grateful to the Editor and four anonymous referees and to Luís Cabral, Jacques Crémer, Thomas Gehrig, Dan Kovenock, Jean-Jacques Laffont, Jean Tirole, Lucy White, Dennis Yao and seminar participants at various Universities and conferences for helpful comments and discussions. Parts of this work were completed while the second author was visiting the Portuguese Competition Authority - he gratefully acknowledges the hospitality.
} 


\begin{abstract}
We analyze a simple dynamic durable good oligopoly model where sellers are capacity constrained. Two incumbent sellers and potential entrants choose their capacities at the start of the game. We solve for equilibrium capacity choices and the (necessarily mixed) pricing strategies. In equilibrium, the buyer splits the order with positive probability to preserve competition; thus it is possible that a high and low price seller both have sales. Sellers command a rent above the value of unmet demand by the other seller. A buyer would benefit from either a commitment not to buy in the future or by hiring an agent with instructions to buy always from the lowest priced seller.
\end{abstract}

JEL numbers: D4, L1

Keywords: Strategic buyers, capacity constraints, bilateral oligopoly, dynamic competition. 


\section{Introduction}

In many durable goods markets, sellers who have market power and intertemporal capacity constraints face strategic buyers who make purchases over time. There may be a single buyer, as in the case of a government that purchases military equipment or awards construction projects, such as for bridges, roads, or airports, and chooses among the offers of a few large available suppliers. Or, there may be a small number of large buyers, as with companies that order aircraft or large ships, where the supply could come only from a small number of large, specialized companies. ${ }^{1}$ The capacity constraint may be due to the production technology: a construction company undertaking to build a highway today may not have sufficiently many engineers or machines available to compete for an additional large project tomorrow, given that the projects take a long time to complete; a similar constraint is faced by an aircraft builder that accepts an order for a large number of aircraft. Or, the capacity constraint may simply correspond to the flow of a resource that cannot exceed some level: thus, if a supplier receives a large order today, he will be constrained on what he can offer in the future. This effect may be indirect, as when the resource is a necessary ingredient for a final product (often the case with pharmaceuticals). More generally, the above cases suggest a need to study dynamic oligopolistic price competition for durable goods with capacity constraints and strategic buyers.

In this paper, we show that the preservation of future competition provides an incentive for a strategic buyer to split early purchase orders. We also demonstrate that the option to split orders leaves a buyer worse off in equilibrium. We illustrate these results with a simple dynamic model. Two incumbent sellers choose capacities and a large number of potential entrants choose their capacities after the incumbents. Capacity determines how much a firm can produce over the entire game. Sellers then set first-period prices, and the buyer decides how many units of the durable good to purchase from each seller. In the second period, given the remaining capacity of each firm,

\footnotetext{
${ }^{1}$ In an empirical study of the defense market, Greer and Liao (1986, p. 1259) find that "the aerospace industry's capacity utilization rate, which measures propensity to compete, has a significant impact on the variation of defense business profitability and on the cost of acquiring major weapon systems under dualsource competition". Ghemawat and McGahan (1998) show that order backlogs, that is, the inability of manufacturers to supply products at the time the buyers want them, is important in the U.S. large turbine generator industry and affects firms' strategic pricing decisions. Likewise, production may take significant time intervals in several industries: e.g., for large cruise ships, it can take three years to build a single ship and an additional two years or more to produce another one of the same type. Jofre-Bonet and Pesendorfer (2003) estimate a dynamic procurement auction game for highway construction in California - they find that, due to contractors' capacity constraints, previously won uncompleted contracts reduce the probability of winning further contracts.
} 
the sellers again set prices and the buyer makes a purchasing decision. Demand has a very simple structure. The buyer has value for three units in total, with the first two having a current and a future utility while the third only has utility in the second period. This is the simplest structure that allows for future demand and the possibility of order splitting in the first period.

Our main results are as follows. First, entry is always blockaded - the incumbent sellers choose capacities such that there is no profitable entry. Second, given these capacity levels, a pure strategy subgame perfect equilibrium in prices fails to exist. This is due to a combination of two phenomena. On the one hand, a buyer has an incentive to split his order in the first period if the prices are close, in order to keep strong competition in the second period. This in turn creates an incentive for sellers to raise their prices. On the other hand, if prices are too "high," each seller has a unilateral incentive to lower his price, and sell all of his capacity. We solve for the mixed strategy equilibrium and show that it has two important properties. The buyer has a strict incentive to split the order with positive probability: when the realized equilibrium prices do not differ too much, the buyer chooses to buy in the first period from both the high price seller and the low price seller. Further, we show that the sellers make a positive economic rent above the profits of serving the buyer's residual demand, if the other seller sold all of his units.

Three implications then follow from the existence of positive economic rents for the sellers. First, the buyer would like to commit to make no purchases in the second period, so as to induce strong price competition in the first period. That is, the buyer is hurt when competition takes place over two periods rather than in one. This result implies that a buyer would prefer not to negotiate frequently with sellers, placing new orders as their needs arise over time but, instead, negotiate at one point in time a contract that covers all possible future needs. ${ }^{2}$ Second, a buyer has the incentive to commit to myopic behavior. In other words, the buyer is hurt by his ability to behave strategically over the two periods and would benefit from a commitment to buy always from the lowest priced firm. ${ }^{3}$ Finally, we note that the buyer has an incentive to vertically integrate with one of the suppliers.

\footnotetext{
${ }^{2}$ For example, in 2002 EasyJet signed a contract with Airbus for 120 new A319 aircraft and also for the option to buy, in addition, up to an equal number of such aircraft for (about) the same price. While the agreed aircraft were being gradually delivered, in 2006 EasyJet exercised the option and placed an order for an additional 20 units to account for projected growth, with delivery set between then and 2008. Similarly, an order was placed in 2006 by GE Commercial Aviation to buy 30 Next Generation 737s from Boeing and also to agree to an option for an additional 30 such aircraft.

${ }^{3}$ For example, many government procurement rules do not allow purchasing officers to exercise discretion.
} 
Our study of competition with a strategic buyer and two sellers who face dynamic (intertemporal) capacity constraints is broadly related to two literatures. The first is the literature on capacityconstrained competition. Many of these papers identify the "nonexistence" of a price equilibrium (Dasgupta and Maskin (1986), Osborne and Pitchik (1986), Gehrig (1990), and others). Several other papers have studied the choice of capacity in anticipation of oligopoly competition and the effects of capacity constraints on collusion; see, for example, Kreps and Scheinkman (1983), Lambson (1987), Allen, Deneckere, Faith, and Kovenock (2000), and Compte, Jenny and Rey (2002). In this literature capacity constraints operate on a period-by-period basis. Dynamic capacity constraints, the focus of our paper, have received much less attention in the literature. Griesmer and Shubik (1963) and Dudey (1992) study games where capacity-constrained duopolists face a finite sequence of identical buyers with unit demands. Besanko and Doraszelski (2004) study a dynamic capacity accumulation game with price competition. Ghemawat (1997, ch.2) and Ghemawat and McGaham (1998) characterize mixed strategy equilibria in a two-period duopoly (with one seller having initially half of the capacity of the other). Garcia, Reitzes, and Stacchetti (2001) examine hydro-electric plants that can use their capacity (water reservoir) or save it for use in a later period. Bhaskar (2001) shows that, by acting strategically, a buyer can increase his net surplus when sellers are capacity constrained. In his model, however, there is a single buyer who has unit demand in each period for a perishable good, and so "order splitting" cannot be studied. ${ }^{4}$ Dudey (2006) presents conditions such that a Bertrand outcome is consistent with capacities chosen by the sellers before the buyers arrive. In the above mentioned papers, demand is modeled as static and independent across periods. The key distinguishing feature of our work is that the buyer (and not just the sellers) are strategic and the evolution of capacities across periods depends on the actions of both sides of the market.

Second, our work is related to the procurement literature where both buyers and sellers are strategic. Of particular relevance is the work that examines a buyer who influences the degree of competition among (potential) suppliers, as in the context of "split awards" and "dual-sourcing." Anton and Yao (1989 and 1992) consider models where a buyer can buy either from one seller or split his order and buy from two sellers, who have strictly convex cost functions. They find conditions under which a buyer will split his order and characterize seemingly collusive equilibria.

\footnotetext{
${ }^{4}$ The buyer can chose not to buy in a given period, thus receiving zero value in that period, but obtaining future units at lower prices. The buyer in our model views the good as durable and may wish to split the order, possibly buying from the more expensive supplier in the first period. Our focus and set of results are, thus, quite different.
} 
Inderst (2006) examines a model similar to the work of Anton and Yao but with multiple buyers. He demonstrates that having multiple buyers increases the incentive to split their orders across sellers. A mechanism approach to dual-sourcing is offered by Riordan and Sappington (1987). We depart from this literature in two important directions. First, the intertemporal links are at the heart of our analysis: the key issue is how purchasing decisions today affect the sellers' remaining capacities tomorrow. In contrast, the work mentioned above focuses on static issues and relies on cost asymmetries. Second, strategic purchases from competing sellers and a single buyer in a dynamic setting are also studied under "learning curve" effects; see e.g. Cabral and Riordan (1994) and Lewis and Yildirim (2002). In our case, by buying from one seller a buyer makes that seller less competitive in the following period. In the learning curve case, that effect is reversed, due to unit cost decreases.

The remainder of the paper is organized as follows. The model is set up in Section 2. In section 3 we derive the equilibrium and discuss a number of implications. We conclude in Section 4. Proofs are relegated to an Appendix.

\section{The model}

The buyer and sellers interact over two periods. There are two incumbents and many potential entrants on the seller side of the market. The product is perfectly homogeneous and perfectly durable over the lifetime of the model. All players have a common discount factor $\delta$.

The buyer values each of the first two units at $V$ in each period that he has the unit and a third unit at $V_{3}$ in only period 2 . Thus, for each of the first two units purchased in period 1 , the buyer gets consumption value $V$ in each period. We assume that $V \geq V_{3}>0 .{ }^{5}$

At the start of the game the incumbent sellers simultaneously choose their capacities. The potential entrants observe the incumbents' capacity choices and then simultaneously choose whether to enter and their capacity choice if they enter. We assume that the cost of capacity for any seller is small, $\varepsilon$, but positive; throughout the paper, all profit levels are gross of the capacity costs. The marginal cost of production is 0 . The capacity choice is the maximum that the seller can produce

\footnotetext{
${ }^{5}$ The maximum discounted gross value that a buyer could obtain over both periods is equal to $2 V(1+$ $\delta)+\delta V_{3}$. Our specification is consistent with growing demand. Note that, in general, the first and second units could have different values ( say $V_{1} \geq V_{2}$ ). Also, we could allow the demand of the third unit to be random. It is straightforward to introduce either of these cases in the model, with no qualitatitive change in the results, but at the cost of some additional notation.
} 
over the two periods. Thus, each seller has capacity at the beginning of the second period equal to initial capacity less the units sold in the first period. In each period, each of the sellers sets a per unit price for his available units of capacity. The buyer chooses how many units to purchase from each seller at the price specified, as long as the seller has enough capacity. Provisionally, we assume that the capacity choice at the start of the game for each incumbent seller is equal to 2 and that entry is blockaded. Later, we demonstrate that when the third unit has significant economic value, these are the equilibrium capacity choices. We assume that sellers commit to their prices one period at a time and that all information is common knowledge and symmetric. We solve for subgame perfect equilibria of the game.

Let us now discuss why we have adopted this modelling strategy. We analyze a dynamic bilateral oligopoly game, where all players are "large" and are therefore expected to have market power. In such cases, one wants the model to reflect the possibility that each player can exercise some market power. By allowing the sellers to make price offers and the buyer to choose how many units to accept from each seller, all players have market power in our model. It follows that quantities and prices evolve from the first period to the second jointly determined by the strategies adopted by the buyer and the sellers. If, instead, we allowed the buyer to make price offers, then the buyer would have all the market power and the price would be zero. ${ }^{6}$ In fact, anticipating such a scenario, sellers would not be willing to pay even an infinitesimal entry cost and, thus, such a market would never open. There are further advantages of this modeling strategy. First, with sellers making offers, our results are more easily comparable with other papers in the literature. Further, there may be agency (moral hazard) considerations that contribute to why in practice we typically see the sellers making offers. ${ }^{7}$

The interpretation of the timing of the game is immediate in case the sellers' supply comes from an existing stock (either units that have been produced at an earlier time, or some natural resource

\footnotetext{
${ }^{6}$ Inderst (2006) demonstrates that giving multiple buyers the right to make offers that has a significant impact on results due to the convexity of the sellers' cost functions. In our model of constant marginal costs, where a seller has capacity in place, the buyer will always buy a unit at a price of 0 if the buyer can make offers.

${ }^{7}$ In general we see the sellers making offers, even with a single buyer, as when the Department of Defense (DOD) is purchasing weapon systems. The DOD may do this to solve possible agency problems between the agent running the procurement auction and the DOD. If an agent can propose offers, it is much easier for sellers to bribe the agent to make high offers than if sellers make offers, which can be observed by the regulator. This is because the sellers can bribe the agent to make high offers to each of them, but competition between the sellers would give each seller an incentive to submit a low bid to make all the sales and it would be quite difficult for the agent to accept one offer that was much higher than another.
} 


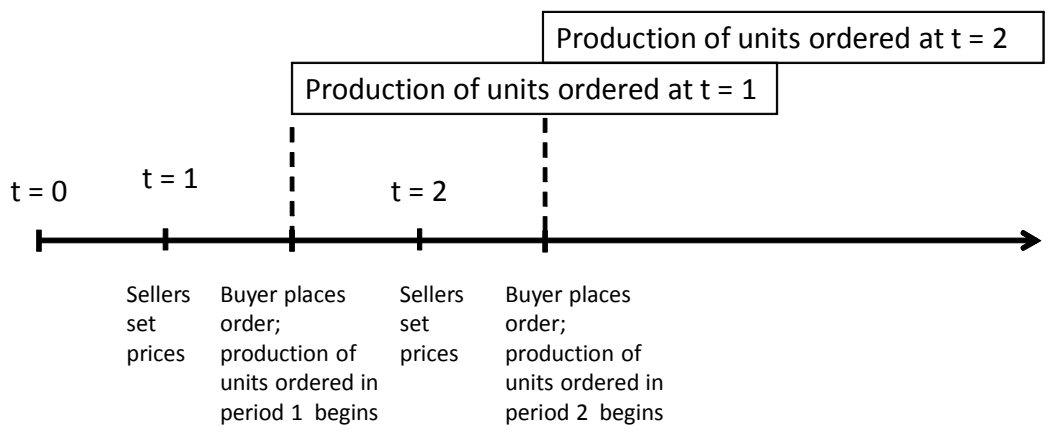

Figure 1: Timing

that the firm controls). One simple way to understand the timing in the case where production takes place in every period is illustrated in Figure 1. The idea here is that actual production takes time. Thus, orders placed in period 1 are not completed before period two orders arrive. Since each seller has the capacity to work only on a limited number of units at a time, units ordered in period one restrict how many units could be ordered in period two. In such a case, since our interpretation involves delivery after the current period, the buyer's values specified in the game should be understood as the present values for these future deliveries (and the interpretation of discounting should also be accordingly adjusted).

\section{Equilibrium}

We are constructing a subgame perfect equilibrium and, thus, we work backwards from period 2 . After finding the period 2 subgame outcomes, we derive buyer demand and find the equilibrium pricing strategies for period 1 . Next, we identify possible buyer actions to modify the competition and limit seller rents. Finally, we examine equilibrium capacity choices by sellers. 


\subsection{Second period}

There are several cases to consider, depending on how many units the buyer purchased from each seller in period 1 . Let $B$ denote the remaining units of buyer demand, and let $C_{i}$ denote a seller with $i$ units of remaining capacity. If the buyer purchased 3 units in period 1 , the game is over as there is no remaining demand in period 2. The substantive subgame cases are:

Buyer purchased two units in period 1. If the buyer bought a unit from each of the sellers in period 1 , then the price in period 2 is 0 due to Bertrand competition; each of the $C_{1}$ sellers earns a profit of 0 . If the buyer purchased 2 units from the same firm, then the other firm becomes a monopolist in period 2 and charges $V_{3}$; the period 2 equilibrium profit of the $C_{2}$ seller is $V_{3}$ and, of course, the $C_{0}$ seller earns 0 .

Buyer purchased one unit in period 1. In this case, the buyer has demand for $B=2$ units, and there is one $C_{2}$ seller and one $C_{1}$ seller. There is no pure strategy equilibrium in this case. There exists a mixed strategy equilibrium in which seller $C_{2}$ 's profit is $V_{3}$ and seller $C_{1}$ 's profit is $V_{3} / 2$,

the support of the prices is from $V_{3} / 2$ to $V_{3}$, and the price distributions are $F_{1}(p)=2-\frac{V_{3}}{p}$ for seller $C_{1}$, and $F_{2}(p)=1-\frac{V_{3}}{2 p}$ for $p<V_{3}$ with a mass point of $\frac{1}{2}$ at $p=V_{3}$ for seller $C_{2}$.

Buyer purchased no units in period 1. Each seller enters period 2 with 2 units of capacity, while the buyer has demand for 3 units. Again, there is no pure strategy equilibrium. In the mixed strategy equilibrium, each seller's profit is $V_{3}$, the price support is from $V_{3} / 2$ to $V_{3}$, and the distribution is $F(p)=2-\frac{V_{3}}{p}$ for each seller.

Period 2 outcomes highlight two key insights that run throughout the paper (please see the Appendix for verification of equilibrium in the subgames). The first concerns the calculation of the equilibrium sellers' profits and the second regards the ranking of the sellers' price distributions. Let $C_{L}$ and $C_{H}$, where $L \leq H$, denote the low and high capacity seller, respectively. If $C_{L}<B$, then seller $C_{H}$ can guarantee himself a payoff of at least $V_{3}\left(B-C_{L}\right)$ since, no matter what the other seller does, he can always charge $V_{3}$ and sell at least $B-C_{L}$ units. This is seller $C_{H}$ 's security profit level. This is because seller $C_{L}$ can supply only up to $C_{L}$ of the $B$ units of buyer demand, and the buyer is willing to pay at least $V_{3}$. Seller $C_{H}$ 's security profit puts a lower bound on the price offered in period 2. Given seller $C_{H}$ can sell at most $B$ units (that is, the total demand), he will never charge a price below $V_{3}\left(B-C_{L}\right) / B$, since a lower price would lead to a payoff less than his security profit. Since seller $C_{H}$ would never charge a price below $V_{3}\left(B-C_{L}\right) / B$, this level also puts a lower bound on the price seller $C_{L}$ would charge and, as that seller has $C_{L}$ units he could 
possibly sell, his security profit is $C_{L} \frac{V_{3}\left(B-C_{L}\right)}{B} .^{8}$ Competition between the two sellers fixes their profits at their respective security levels.

The second insight deals with the incentives for aggressive pricing. We find that the seller $C_{H}$ will price less aggressively than seller $C_{L}$ in period 2. Seller $C_{H}$ knows that he will make sales even if he is the highest price seller, while seller $C_{L}$ makes no sales if he is the highest price seller. So, seller $C_{L}$ always has an incentive to price more aggressively. More precisely, the $F_{H}$ price distribution first-order stochastically dominates $F_{L}$. This general property has important implications for the quantities sold and the market shares over the entire game.

The equilibrium payoffs in the second period subgames are summarized in Table 1:

\begin{tabular}{|c|c|c|c|}
\hline \multicolumn{4}{|c|}{ Table 1: Period 2 incremental payoffs for $(2,2)$ capacity game } \\
\hline Period 2 $(B, H, L)$ configuration & Buyer Payoff & Seller $C_{H}$ payoff & Seller $C_{L}$ payoff \\
\hline$(3,2,2)$ & $2 V-V_{3}$ & $V_{3}$ & $V_{3}$ \\
\hline$(2,2,1)$ & $V-V_{3} / 2$ & $V_{3}$ & $V_{3} / 2$ \\
\hline$(1,2,0)$ & 0 & $V_{3}$ & 0 \\
\hline$(1,1,1)$ & $V_{3}$ & 0 & 0 \\
\hline
\end{tabular}

\section{$3.2 \quad$ First period}

We use Figure 2 to summarize the buyer's purchasing behavior in period 1. In response to any pair of prices, the buyer maximizes net surplus, including period 2 consequences, by choosing how many units to purchase from each seller. The four regions in Figure 2 correspond to the buyer's optimal choice. First, in the no purchase region, both prices are sufficiently high that the buyer optimally waits until period 2 for a payoff of $\delta\left[2 V+V_{3}-2 V_{3}\right]$, from Table 1 . Defining $\Delta \equiv \delta V_{3}$ as the discounted value of unit 3 , this buyer payoff becomes $2 \delta V-\Delta$. To see that this dominates buying 1 or 2 units in period 1, suppose that $p_{1}$ is the lower of the two prices. Employing Table 1, we see that splitting has a buyer payoff of $2 V(1+\delta)+\Delta-p_{1}-p_{2}$, and the comparison reduces to $2(V+\Delta)<p_{1}+p_{2}$, which corresponds to the line segment between the no purchase and split regions. Similarly, waiting dominates buying 2 units from the lower price seller when the low price is above $V+\Delta / 2$, represented by the vertical (and horizontal) line segments dividing the no purchase and

${ }^{8}$ Note that while $C \frac{V_{3}(B-C)}{B}$ is not strictly speaking the "security" profit of the low-capacity seller, it becomes that after one round of elimination of strictly dominated strategies. More generally, for demand values $V_{1} \geq V_{2} \geq \ldots \geq V_{B}$, seller $C_{H}$ has the monopoly option on the residual demand curve and the security profit level is $\max \left\{V_{B}\left(B-C_{L}\right), V_{B-1}\left(B-C_{L}-1\right), \ldots, V_{B-C_{L}+1}(1)\right\}$. This distinction does not matter for subgames of the initial $(2,2)$ capacity configuration but it does arise for other configuration cases; see the Appendix for details on these other cases. 


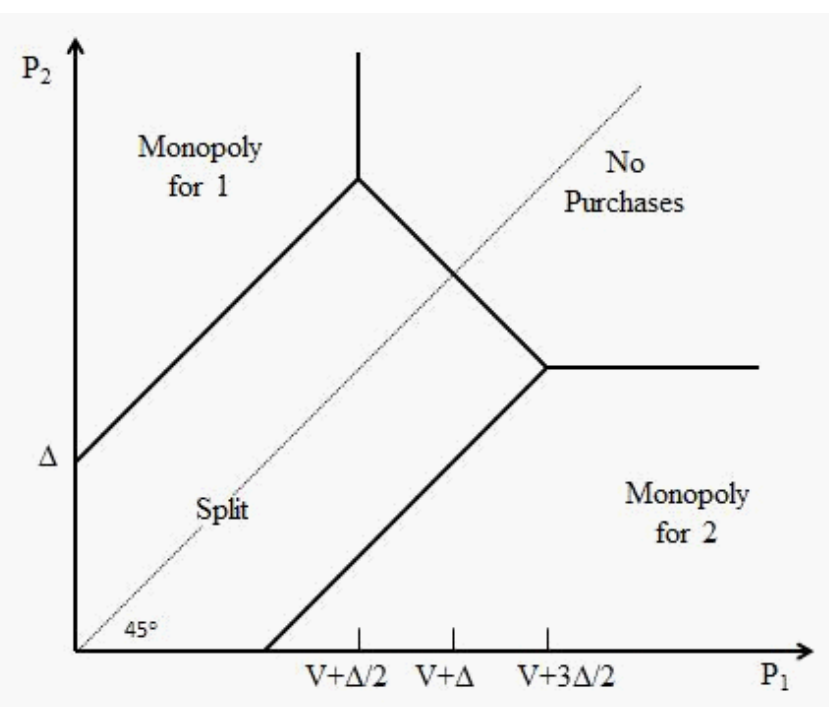

Figure 2: Period 1 demand for $(2,2)$ capacity

monopoly regions. Thus, whenever $p_{1}$ is to the left of the line segment, the buyer will purchase 2 units, and the comparison is then between monopoly for seller 1 and splitting. The buyer will prefer to split whenever the price difference is less than $\Delta$, the buyer's savings from Bertrand competition following a split. Finally, note that indifference holds for prices on the boundary lines. ${ }^{9}$

There is no pure strategy equilibrium in period 1 with this demand structure, a common feature of games with capacity constraints. There is clearly no pure strategy equilibrium with no buyer purchases in period 1. Such a demand outcome requires high prices and either seller can profitably undercut and sell 2 units. For example, even at $p_{1}=p_{2}=V+\Delta$, the lowest prices where the buyer would choose to make no purchase, a price cut to any $\hat{p}<V$ will induce the buyer to purchase 2 units from the deviating seller and, with $\hat{p}$ close to $V$, this will increase his payoff from $\Delta$ to $2 \hat{p}$. As the demand structure in Figure 2 illustrates, it is easy to rule out candidate equilibria where the buyer only purchases 1 unit. The substantive case is where the buyer purchases 2 units. The buyer's incentive is to split when prices are within $\Delta$ of each other. But, if prices are within $\Delta$ of each other then each seller is able to raise his price slightly and still sell a unit. Thus, prices

\footnotetext{
${ }^{9}$ Purchasing more than 2 units is dominated. If both prices are positive, buying 2 units via a split strictly dominates buying 3, since the ensuing Bertrand competition yields a price of 0 for the 3rd unit in period 2 . When $p_{i}=0$ and $p_{j}>\Delta$, purchasing 2 units from $i$ is optimal and strictly dominates purchasing 3 units. If $0 \leq p_{j} \leq \Delta$, splitting and buying 3 units are both optimal choices. Of course, buying 3 units always dominates buying more than 3 units since there is no value for a fourth unit. Finally, on the monopoly-no purchase boundary, the buyer is also indifferent between buying 1 unit. In all other cases, buying 1 unit is not optimal.
} 
must be at least $\Delta$ apart. If the gap is greater than $\Delta$, then the buyer will buy both units from the low price seller. In this case, however, the low price seller can raise his price and still sell two units. The only remaining possibility is a price difference equal to $\Delta$. The buyer will either buy two units from the low price seller, split his order, or mix between the two options. No matter how the buyer's indifference is resolved, there is always a profitable deviation for at least one seller. Thus,

Lemma 1. There is no pure strategy equilibrium in the monopsony model.

Now, we present our results on equilibrium for period 1.

Proposition 1. There exists a mixed strategy equilibrium for period 1 in which the outcome is efficient: the buyer purchases 2 units with probability 1 . The distribution of prices is symmetric and given by

i) For $\Delta<\Delta^{*} \equiv\left(\frac{2}{3+\sqrt{5}}\right) V$,

$$
F(p)=\left\{\begin{array}{cc}
1-(\pi-\Delta) / p & \text { for } \underline{p} \leq p \leq \underline{p}+\Delta \\
2-\pi /(p-\Delta) & \text { for } \underline{p}+\Delta \leq p \leq \bar{p}
\end{array}\right.
$$

where $\underline{p}=\left(\frac{V}{\Delta^{*}}-1\right) \Delta$ and $\bar{p}=\underline{p}+2 \Delta$

ii) For $\Delta \geq \Delta^{*}$,

$$
F(p)= \begin{cases}1-\underline{p} / p & \text { for } \underline{p} \leq p \leq \bar{p}-\Delta \\ 1-\Delta / \underline{p} & \text { for } \bar{p}-\Delta \leq p \leq \underline{p}+\Delta \\ 2-(\underline{p}+\Delta) /(p-\Delta) & \text { for } \underline{p}+\Delta \leq p<\bar{p} \\ 1 & \text { for } p=\bar{p}\end{cases}
$$

where $\underline{p}=\sqrt{V \Delta}$ and $\bar{p}=V+\Delta$.

iii) Equilibrium payoffs are $\pi=\underline{p}+\Delta$ for each seller and $2 V(1+\delta)-2 \underline{p}-\Delta$ for the buyer.

Several fundamental economic properties hold in the equilibrium across the full parameter range for $\Delta$, the value for the third unit. First, the equilibrium is efficient because 2 units are purchased for any realized prices. Since $\bar{p} \leq V+\Delta$, it must be that $p_{1}+p_{2}$ does not exceed the threshold of $2(V+\Delta)$ for purchasing 2 units. Second, the expected seller payoff is always $\underline{p}+\Delta$. This is an important property of the equilibrium incentive structure. By charging $\underline{p}+\Delta$, the seller is guaranteed a sale of exactly one unit. By construction, no price will undercut by more than $\Delta$, and there is no chance of not making a sale. At the same time, the rival seller never charges $\Delta$ more than $\underline{p}+\Delta$, so there is no chance of a monopoly outcome at $\underline{p}+\Delta$. This is reflected by the spread 
of the price support, $\bar{p}-\underline{p}$, which never exceeds $2 \Delta$. Thus, with a sale guaranteed, profit is at least $\underline{p}+\Delta$. Can profit be any larger? If so, then the price distribution is flat within a neighborhood of $\underline{p}+\Delta$. As a result, the price $\underline{p}$ is strictly dominated, since there is no change in sales for a small price increase implying that the price distribution is also flat in a neighborhood of $\underline{p}$, which contradicts the definition of $\underline{p}$. Thus, seller profit is $\underline{p}+\Delta$. The price distribution is then constructed so that every price has an expected payoff of $\underline{p}+\Delta$.

Proposition 1 allows us to assess the impact of dynamic price competition on the buyer and seller sides of the market. The static price competition benchmark, where all purchases must occur in period 1 , has the same price outcome as the period 2 subgame following no purchases in period 1. Thus, the outcome is efficient, static expected profits are $\Delta$, and the buyer expected surplus is $2 V(1+\delta)-\Delta$. Comparing this outcome to that for dynamic price competition, we see that the buyer suffers while the sellers gain. In the dynamic game, the outcome is efficient and social surplus is unchanged from the static game. At $\underline{p}+\Delta$, however, seller profits are strictly higher in the dynamic game. By this measure, competition is less intense in the dynamic game. Intuitively, a buyer splits purchases in the dynamic game even though this increases current expenditures more than buying 2 units from the lowest priced seller. The value to the buyer is the preservation of competition for period 2. The less intense price competition in the dynamic game is associated not only with higher profits, but also with non-overlapping price supports as $\underline{p}$ in the dynamic game is strictly above $\Delta$, the upper limit of the price support in the static game. With an efficient outcome, but higher seller profits, the expected net surplus of the buyer is necessarily lower in the dynamic game. Thus,

Proposition 2. In equilibrium, the expected profit of each seller is greater than $\Delta$, the profit level in the static game. In an efficient equilibrium, the buyer's expected payments in the dynamic game are greater those in the static game.

While the economic structure in terms of efficiency, payoffs relative to the support, and dynamic versus static comparisons do not vary with the value of the buyer units, $\Delta$ and $V$, the quantitative dimensions of the equilibrium price distribution do. The required changes in the distribution commence when $\Delta$ crosses a threshold relative to $V$. For $\Delta$ below the threshold, no part of the equilibrium depends on $V$. The price spread $(\bar{p}-\underline{p})$ is always $2 \Delta$ and equilibrium prices are strictly below the no purchase demand region $(V+\Delta)$. The distribution $F$ is continuous and atomless, but it has a kink at $\underline{p}+\Delta$. See Figure 3 for details. For $\Delta$ above the threshold, the equilibrium distribution depends on $V$. Now, the price spread is less than $2 \Delta$, and the $\bar{p}$ is equal to $V+\Delta$. 


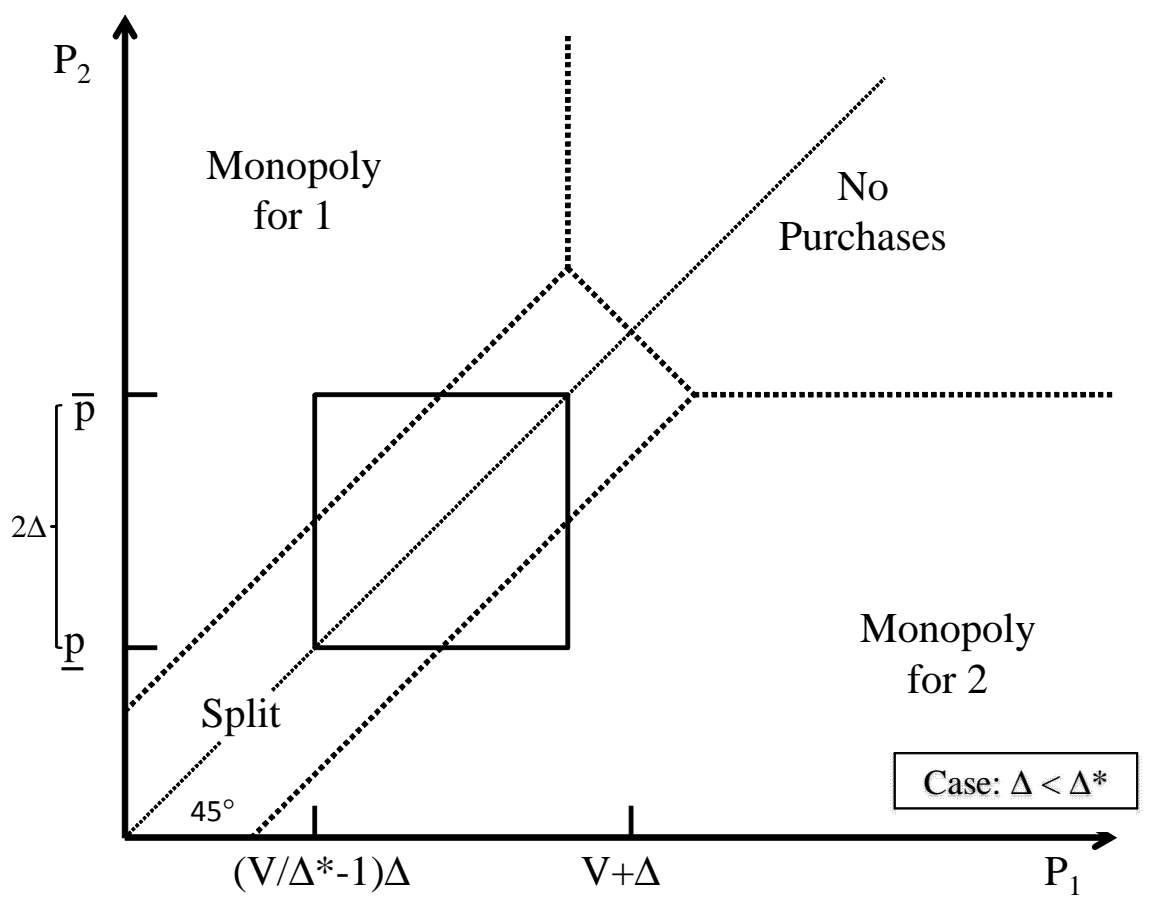

Figure 3: Equilibrium support when $\Delta$ is small

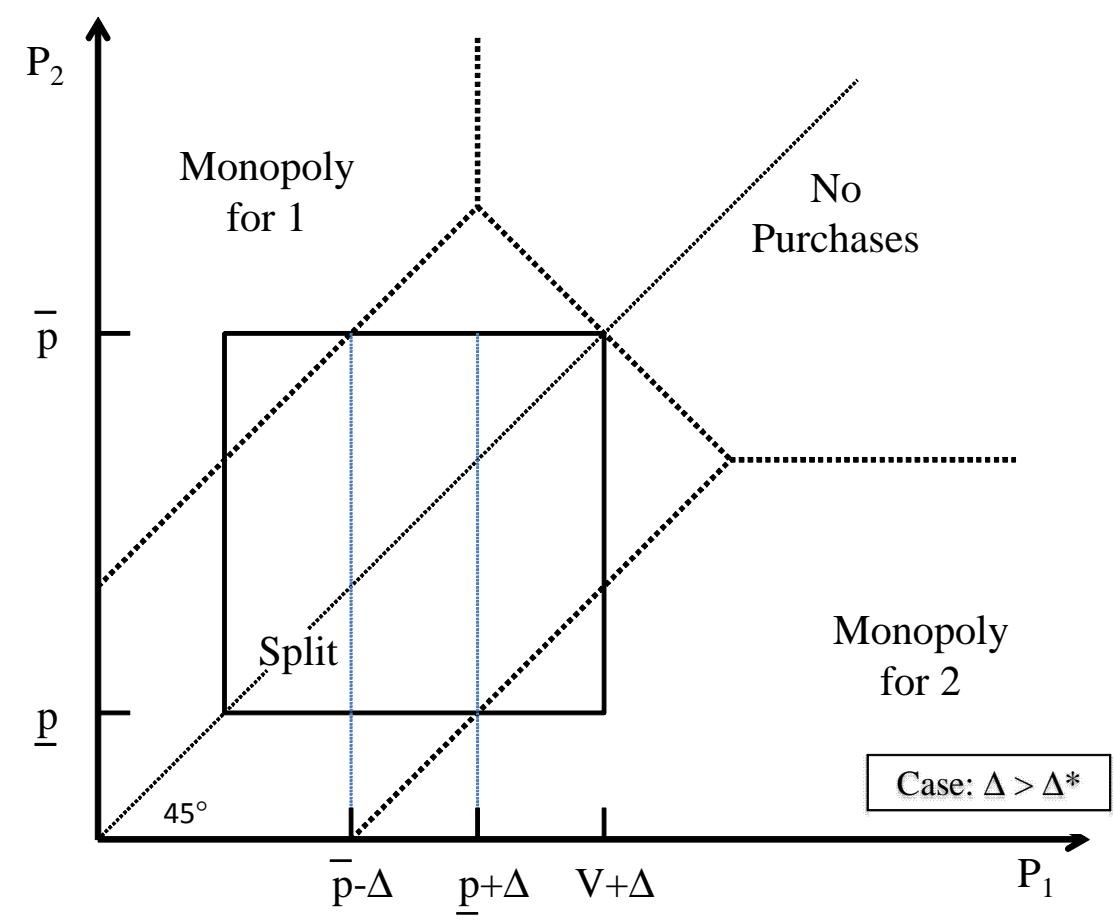

Figure 4: Equilibrium when $\Delta$ is large 
Furthermore, the price distribution rises smoothly at low prices, has a gap, then rises smoothly again, and then has an atom at $\bar{p}=V+\Delta$. When $\Delta$ is large, the form of the distribution for low $\Delta$ creates a profitable deviation to prices just below $p$. To maintain incentives, it is necessary to compress the price spread from $2 \Delta$. But this implies that $\bar{p}-\Delta$ is now below $p+\Delta$, and prices between these values are strictly dominated since demand is always in the split region for any price offered by the other firm (see Figure 4). As a result, the distribution has a gap in this region. In turn, an atom is required at $\bar{p}$ in order for the highest price before the gap, $\bar{p}-\Delta$, to yield the equilibrium profit $p+\Delta$. Intuitively, the "missing mass" from the gap is redistributed as an atom at $\bar{p}$ so that low prices yield a sufficiently high probability of a monopoly outcome. ${ }^{10}$

\subsection{Possible actions by the buyer to reduce sellers' rents}

As we saw above (Proposition 2), in the equilibrium each seller's profit exceeds $\Delta$. This is an important property and we now discuss some of its implications. We illustrate three strategies that the buyer can use to reduce his expected payments and still preserve efficiency. First, the buyer benefits if he can commit to make all his purchases at once, effectively collapsing the game into a one-shot interaction. Second, we show that the buyer has an incentive to commit to (myopic) period-by-period optimization. Third, we demonstrate that the buyer will benefit by acquiring one of the sellers.

These three observations help to demonstrate the fundamental force underlying the equilibrium: due to strategic considerations, the buyer does not always purchase from the lowest price seller when he plans to make further purchases, giving sellers the incentive to raise their prices above the static equilibrium level. As the buyer is "hurt" by acting strategically across the two periods of the game, we show that there are actions he can take (e.g. through some unilateral policy commitments) to effectively change the game. In cases when such actions are possible, we thus identify reasons why the buyer would like to choose them. Our first observation is:

Corollary 1 The buyer would benefit from a commitment not to purchase any units in period 2.

The equilibrium seller profit level described in Proposition 2 is larger than in the static equi-

\footnotetext{
${ }^{10}$ We have assumed $0<\Delta<V$. In the limit, as $\Delta \rightarrow 0$, the mixed strategy equilibrium converges to pure Bertrand competition for 2 units of demand (both prices are 0). As $\Delta \rightarrow V$, the distribution collapes to $p=\bar{p}=2 V$. Furthermore, for $\Delta$ above a threshold $\Delta^{* *}>\Delta^{*}$, we are able to construct inefficient equilibria, where the demand outcome is either a split or no purchase. Seller payoffs are less than the profits for the equilibrium in Proposition 1, but above the static benchmark; see Appendix for details.
} 
librium (when the buyer commits to buying all goods in period 1). Recall that the static outcome coincides with the period 2 equilibrium following no sales in period 1 , where each seller earns $V_{3}$ and the buyer purchases 3 units. Viewed as a static game, this becomes an efficient outcome (no discounting). Thus, both outcomes are efficient but the static game has lower seller profits and hence a larger residual of the social surplus remains for the buyer.

The behavior described in Corollary 1 would require, of course, some vehicle of commitment that would make future purchases not possible. This is an interesting result and can be viewed as consistent with the practice of airliners placing a large order that often involves the option to purchase some aircraft in the future at the same price for firm orders placed now. Such behavior is sometimes attributed to economies of scale - our analysis shows that such behavior may emerge for reasons purely having to do with how sellers compete with one another. Our second observation is:

Corollary 2 The buyer would benefit from a commitment to myopic behavior under which purchases are made on the basis of static optimization (in each period).

Suppose that the buyer could commit to myopic behavior. That is, for period 1 purchases, the buyer only values the current units (2 units, each valued at $V(1+\delta))$. Of course, period 2 purchase decisions are unchanged. As a result, a myopic buyer ignores the strategic link between the periods. Further, in period 1 a myopic buyer will always purchases units from the lowest priced seller (as long as this price is below $V(1+\delta))$. There are two possible ways to generate a pure strategy equilibrium with a myopic buyer. First, in equilibrium each seller charges $\Delta / 2$ in the first period and the buyer purchases two units from one seller. Then, the other seller charges a price of $V_{3}$ in the second period and the buyer purchases one unit. Thus, the buyer pays a total of $2 \Delta$. To see that this is an equilibrium, first observe that the buyer indeed behaves optimally, on a period by period basis. Furthermore, neither seller has a profitable deviation. In period 1, if a seller lowers his price below $\Delta / 2$, he then sells both units but obtains a lower profit. If he raises his price, he sells no units in the first period but obtains a profit equal to $V_{3}$ in the second.

There is, however, the possibility that the buyer may split his order (given myopia, the buyer is indifferent between splitting or not) may be viewed as a weakness of the equilibrium described just above. This can be easily addressed in the second possible way to establish an equilibrium, if we introduce a smallest unit of account, $\tau$. The equilibrium has one seller charging $\Delta / 2-\tau$ and the other seller charging $\Delta / 2$ in the first period and the buyer buying two units from the low price seller. The seller that made no sales in the first period, charges $V_{3}$ in the second period and the 
buyer purchases one unit from that seller. Thus, total payment in present value terms for the buyer is $2 \Delta-2 \tau$. Clearly, the equilibrium payoffs are essentially the same under both approaches.

The underlying intuition for Corollary 2 is that a seller knows that if he sets a higher price than his rival he cannot sell a unit in period one (and can only obtain a second period profit of $V_{3}$ ). The above comparison may provide a rationale for policies of large buyers that require purchasing in each situation strictly from the lowest price seller. In particular, a government may often assume the role of such a large buyer. It is often observed that, even when faced with scenarios like the one examined here, governments require that purchasing agents buy only from the low-price supplier, with no attention paid to the future implications of these purchasing decisions. While there may be other reasons for such a commitment policy (such as preventing corruption and bribes for government agents), our analysis suggests that by "tying its hands" and committing to purchase from the seller that sets the lowest current price, the government manages to obtain a lower purchasing cost across the entire purchasing horizon. We find, in other words, that delegation to a myopic purchasing agent is beneficial: it intensifies competition among sellers.

Suppose that a buyer can acquire a seller after he has chosen his capacity. A further implication of Proposition 2 is:

Corollary 3 The buyer has a strict incentive to acquire one of the sellers, that is, to become vertically integrated.

This result is based on the following calculations. By vertically integrating, and paying the equilibrium profit of a seller when there is no integration, $\pi$, the total price that the buyer will pay is $\pi+\Delta$ since the other seller would charge the monopoly price $V_{3}$ for a third unit (sold in period 2 ). This total payment is strictly less than the total expected payment $(2 \pi)$ that the buyer would otherwise make in equilibrium. Thus, even though the other seller will be a monopolist, the buyer's payments are lower, since the seller that has not participated in the vertical integration has lower profits. $^{11}$

\footnotetext{
${ }^{11}$ In our analysis, sellers use linear prices. It should not be too surprising that the application of nonlinear pricing would lead to different results. This case would be relevant when a seller can price the sale of one unit separately from the sale of two units. In an earlier working paper, Biglaiser and Vettas (2004) shows that with a monopsonist under nonlinear pricing, there are unique pure strategy equilibrium payoffs with each seller making profit equal to $\Delta$. In period 1 , both sellers charge $\Delta$ for both a single unit and two units and the buyer buys either two or three units. The ability of each seller to price each of his units separately changes the strategic incentives, intensifies price competition and allows us to derive an equilibrium where the sellers make no positive rents.
} 


\subsection{Initial capacity choices by sellers}

Thus far, we have conducted the analysis assuming exogenous capacity levels, where each seller has 2 units. Now, suppose that their capacity choices are endogenous and other firms are free to enter. We claim that when the discounted value of the third unit, $\Delta$, is significant relative to the other units, then there is an equilibrium in which each firm acquires 2 units of capacity. The endogenous capacity game is the following:

- Incumbents simultaneously choose their capacities

- Entrants observe incumbent capacity choices and simultaneously choose their capacities

- Firms that have positive capacity levels follow the timing as depicted in Figure 1

Assume that the cost of capacity is $\varepsilon$ per unit and focus on the limiting case of $\varepsilon \rightarrow 0$. We then have the following proposition.

Proposition 3. If $\Delta \geq V / 2$, then the capacity game has an equilibrium where each incumbent chooses 2 units of capacity and there is no entry.

To understand the basic forces at work, consider first whether entry is profitable when the incumbents each have two units of capacity. As shown in Proposition 1, each incumbent makes a positive profit in a $(2,2)$ capacity configuration. Entry, however, always results in Bertrand competition where no firm makes positive profits. The smallest entry event is the $(2,2,1)$ capacity outcome, where one entrant has one unit of capacity. Even then, the market collapses to Bertrand competition. Furthermore, any period 2 subgame yields 0 profits for all sellers, since there is either an excluded seller or a seller with excess capacity. Given this, equilibrium requires that all firms choose a price of 0 in period 1 . Thus, entry is not profitable.

In view of the positive profits of incumbents, consider whether incumbent capacity expansion is profitable. Recall that in a $(2,2)$ capacity setting, each firm can guarantee $\Delta$ in profits because the other incumbent cannot supply the entire buyer demand. When the configuration is $(3,2)$, this logic breaks down and the $C_{2}$ firm is more aggressive in period 1. In equilibrium, the buyer will purchase 2 units from the $C_{3}$ seller in period 1 more often than in $(2,2)$. In particular, if the $C_{3}$ seller has a lower price than the $C_{2}$ seller in period 1, then the buyer will always buy 2 units from the lower priced seller: this preserves Bertrand competition in period 2 and there is no need for the buyer to split the order and pay a premium to include the higher price firm in the split. This 
makes the $C_{2}$ seller price more aggressively and lowers the profits of the $C_{3}$ seller. In the mixed strategy equilibrium for $(3,2)$, while the price supports intervals overlap, the price distribution of $C_{3}$ first order stochastically dominates that for $C_{2}$. In equilibrium, the $C_{3}$ seller has a strictly lower payoff than a $C_{2}$ seller in $(2,2)$. Thus, capacity expansion is never profitable.

With respect to a capacity reduction, from $(2,2)$ to $(2,1)$, the profit assessment is more subtle. When the value of the third unit is significant, $\Delta \geq V / 2$, then the capacity reduction leads to lower profits for the $C_{1}$ firm. On the other hand, as $\Delta \rightarrow 0$, the $(2,2)$ capacity equilibrium converges to pure Bertrand competition, while in $(2,1)$ both firms make strictly positive profits. The reason is that in the $(2,1)$ configuration the $C_{2}$ seller will never price below $V(1+\delta) / 2$, a lower bound that does not depend on the value of the third unit. This is a consequence of buyer demand in period 1: as long as $C_{2}$ sets a price below $V(1+\delta)$, the buyer will purchase at least one unit from $C_{2}$. Depending on the price from $C_{1}$, the $C_{2}$ seller might also sell a second unit in the first period but, since $C_{1}$ only has 1 unit of capacity, $C_{2}$ is guaranteed a profit of at least $\Delta$ on its second unit. Hence, $C_{2}$ can guarantee a payoff of at least $V(1+\delta)+\Delta$ and, with 2 units of capacity, will never price below $1 / 2$ of $V(1+\delta)+\Delta$. Given this, the $C_{1}$ seller can price at $1 / 2$ of $V(1+\delta)+\Delta$ and be assured of a sale and hence a profit that remains positive even as $\Delta \rightarrow 0$. Thus, as a measure of competitive pressure, it is $V$ rather than $\Delta$ that matters in $(2,1)$ when the third unit is of vanishing value.

In contrast, it is $\Delta$ rather than $V$ that functions as the "marginal value" with respect to competitive pressure when the configuration is $(2,2)$ when $\Delta>V / 2$. From Proposition 1 , the rate of profit growth in $\Delta$ is greater than 1 . As a result, the profit difference between $(2,2)$ and $(2,1)$ for the $C_{1}$ seller rises with $\Delta$. As $\Delta$ crosses $\Delta^{*}$, this difference is sufficiently large that it dominates the security profit component of $V(1+\delta) / 2$ for the $C_{1}$ seller in the $(2,1)$ configuration. Intuitively, additional capacity is valuable for the $C_{1}$ seller when the marginal value of the third unit is large. Thus, a $(2,2)$ configuration is neiher susceptible to capacity deviations by incumbents nor attractive to entrants.

\section{Conclusion}

Capacity constraints play an important role in oligopolistic competition. In this paper, we have examined markets where both sellers and the buyer act strategically. Sellers have intertemporal capacity constraints, as well as the power to set prices. The buyer decides which sellers to buy 
from, taking into consideration that current purchasing decisions affect the intensity of competition in the future. Capacity constraints imply that a pure strategy equilibrium fails to exist. Instead, sellers play a mixed strategy with respect to their pricing, and the buyer may split the order. Importantly, we find that the sellers enjoy higher profits than they would have in an one-shot interaction (or, equivalently, the competitive profit from satisfying residual demand). The buyer is hurt, in equilibrium, by the ability to behave strategically over the two periods, since this behavior allows the sellers to increase their prices above their rival's and still sell their products. Thus, the buyer has a strict incentive to commit not to buy in the future, or to commit to myopic, period-byperiod maximization (perhaps by delegating purchasing decisions to agents), as well as to vertically integrate with one of the sellers.

This is, to our knowledge, one of the first papers to consider capacity constraints and strategic buyer behavior in a dynamic setting. In an earlier working paper, Biglaiser and Vettas (2004), examined the model when there were multiple buyers and allowed non-linear pricing. When there are multiple buyers and linear pricing, they found that the sellers were able to capture rents above the value of the marginal unit $\Delta$. The idea is that if each of $N$ buyers purchased 2 units in period 1, and the sellers had equal remaining capacity ( $N$ of the original $2 N$ units), then Bertrand competition would ensue in period 2. This outcome involves both implicit coordination by buyers in period 1 and aggregate order splitting. With non-linear pricing, they found in the monopsony case that the sellers' payoffs were held to the value of the marginal unit $(\Delta)$; interestingly, they found that the sellers still retain rents in the duopsony case.

With regard to future work, it would be interesting to consider the case where the products offered by the two sellers are differentiated. Is there a distortion because buyers strategically purchase products different from their most preferred ones, with the purpose of intensifying competition in the future? Another direction to consider is an alternative price determination formulation. For instance, sellers may be able to make their prices dependent on the buyers' purchasing behavior e.g. by offering a lower price to a buyer that has not purchased in the past: "loyalty discount" and other quantity based price discrimination mechanisms.

\section{Appendix}

Period 2 subgames for $(2,2)$ capacity. We verify the claims in the text for equilibria in the period 2 subgames. Case (a): The buyer purchased 2 units. There are two subgames. If $\left(B, C_{H}, C_{L}\right)=(1,2,0)$, then the unique outcome is $p_{H}=V_{3}$ and the buyer purchases 1 unit from seller $C_{H}$. If $\left(B, C_{H}, C_{L}\right)=(1,1,1)$, then the unique outcome is that both sellers charge 0 , and the 
buyer purchases one unit (due to standard Bertrand analysis). Case (b): buyer purchased 1 unit. The subgame is $\left(B, C_{H}, C_{L}\right)=(2,2,1)$. Demand is more subtle than in case (a), since the buyer may purchase up to 2 units. Figure 5A shows the demand outcome for any pair of prices. We need to show that the price distributions specified in the text form a mixed strategy equilibrium. By construction, any price in the support yields a payoff of $V_{3}$ for seller $C_{2}$ and $V_{3} / 2$ for seller $C_{1}$. Consider seller $C_{2}$. At any price $p<V_{3} / 2$, the buyer purchases 2 units from $C_{2}$ and the payoff is $2 p$ which is less than $V_{3}$. At any price $p>V_{3}$, the buyer purchases 1 unit from seller $C_{1}$. Thus, $C_{2}$ has a payoff of 0 . Analogous arguments hold for seller $C_{1}$. Thus, it is optimal for each seller to price according to the specified distributions. Case (c): buyer made no purchases. The subgame is symmetric and $\left(B, C_{H}, C_{L}\right)=(3,2,2)$. The buyer may now purchase up to 3 units and Figure $5 \mathrm{~B}$ shows the demand outcome across prices. By construction, any price in the support yields a payoff of $V_{3}$ for each seller. If a seller offers a price $p<V_{3} / 2$, then the buyer purchases 2 units from that seller and the payoff is $2 p$ which is less than $V_{3}$. At any price $p>V_{3}$, the buyer purchases 2 units from the other seller, but no units at price $p$. Thus, the deviating seller has a payoff of 0 . Thus, it is optimal for each seller to price according to the specified distribution.

Proof of Lemma 1. Suppose, to the contrary, that we have an equilibrium at some $\left(p_{L}, p_{H}\right)$. Without loss of generality, we label prices so that $p_{L} \leq p_{H}$ and refer to payoffs $\pi_{L}$ and $\pi_{H}$ for the $L$ (low) and $H$ (high) seller, respectively. First, observe that any price above $V+3 \Delta / 2$ leads to a payoff of $\Delta$. This is because, by demand in Figure 2, there are no period 1 sales for this seller and, by Table 1, the period 2 payoff is $V_{3}$. This implies that any price below $\Delta / 2$ is strictly dominated since, with a capacity of 2 units, the payoff at such a price is less than $\Delta$. Next, consider $p_{L}>V+\Delta$. With $p_{H} \geq p_{L}$, we are in the No Purchases region for demand and we have $\pi_{L}=\Delta$. But then $L$ can profitably deviate to a price $p$ where $\Delta<p<V+\Delta$ and be assured of selling at least 1 unit for a payoff greater than $\Delta$.

This leaves candidate equilibria where $\Delta / 2 \leq p_{L} \leq V+\Delta$. Referring to demand in Figure 2, we see that $\left(p_{L}, p_{H}\right)$ cannot be interior to any of the three demand regions (above the $45^{\circ}$ line). In either of the Monopoly (for $L$ ) or the Split regions, a slight increase in $p_{L}$ would leave demand unchanged while resulting in a larger payoff for $L$. In the No Purchases region, we know from above that $\pi_{L}=\Delta$ and, by $p_{L} \leq V+\Delta$, that $p_{H} \geq V+\Delta$ holds for $\left(p_{L}, p_{H}\right)$ in this region. Then, we see that any price $p<p_{H}-\Delta$ implies that the demand outcome at $\left(p, p_{H}\right)$ is Monopoly for $L$ and a payoff of $2 p$. But $2\left(p_{H}-\Delta\right) \geq 2 V>\Delta$, so $L$ has a profitable deviation.

The remaining possibility is that $\left(p_{L}, p_{H}\right)$ lies on one of the three boundary lines (above the $45^{\circ}$ 
line) in Figure 2. The first case is the vertical line segment of $p_{L}=V+\Delta / 2$ and $p_{H} \geq V+3 \Delta / 2$ along which the buyer is indifferent between No Purchase, 1 unit from $L$, and 2 units from $L$. If the buyer chooses No Purchases, then $L$ has a payoff of $\Delta$; at a purchase of 1 unit, $L$ has a payoff of $p_{L}$. Since any price $p<p_{L}$ implies 2 units for $L$ and a payoff of $2 p$, it must be that the buyer chooses 2 units from $L$ with probability 1 in response to $\left(p_{L}, p_{H}\right)$ since any other buyer choice would leave $L$ with a profitable deviation. This implies that $\pi_{H}=\Delta$. But then $H$ can profitably deviate to any price $p$ where $V+\Delta / 2<p<V+3 \Delta / 2$ as this guarantees a sale of 1 unit and a payoff of at least $V+\Delta / 2>\Delta$. Thus, there is no equilibrium in this case.

The second case is the boundary between the Split and No Purchases, $p_{H}=2(V+\Delta)-p_{L}$ for $V+\Delta / 2 \leq p_{L} \leq V+\Delta$. Note that $L$ can guarantee a monopoly outcome by deviating to any $p<p_{H}-\Delta$. Since

$$
2\left(p_{H}-\Delta\right)=2\left(2 V+\Delta-p_{L}\right)>\pi_{L}=p_{L} \quad \Leftrightarrow \quad 4 V+2 \Delta>3 p_{L}
$$

on this boundary, we see from $p_{L} \leq V+\Delta$ that the last inequality above is guaranteed by $V>\Delta$. Thus, $L$ has a profitable deviation.

The last case is the Split and Monopoly boundary, $p_{H}=p_{L}+\Delta$ for $\Delta / 2 \leq p_{L} \leq V+\Delta / 2$, where the buyer is indifferent between the two choices. As in the first case, $L$ can guarantee a sale of 2 units by offering a lower price, although in this case any $p<p_{L}$ will suffice. Since this yields a payoff of $2 p$, it must be that the buyer chooses Monopoly for $L$ with probability one. This implies $\pi_{H}=\Delta$. But $H$ can guarantee a sale of 1 unit by offering any $p<p_{L}+\Delta$. Thus the lower bound of $\Delta / 2 \leq p_{L}$ implies that $H$ has a profitable deviation and there is no equilibrium in this case.

Proof of Proposition 1. For the distributions specified in the text, we need only verify that prices within the supports are optimal, while deviations to prices outside the supports are unprofitable. The undiscounted period 2 subgame payoffs are in the text in Table 1. From that table, we compare payoffs across the feasible set of buyer period 1 choices and arrive at the demand pattern in Figure 2 in the text. We then construct the profit function by calculating demand at pairs of prices, and take expectations over the rival's price using the distribution specified in the proposition. First, we examine the case when $\Delta<\Delta^{*}$. Calculating the profit function, we find that for $p \leq \bar{p}$

$$
\pi(p)= \begin{cases}2 p & \text { for } p \leq p-\Delta \\ p[2-F(p+\Delta)] & \text { for } \bar{p}-\bar{\Delta} \leq p \leq p+\Delta \\ p-(p-\Delta) F(p-\Delta) & \text { for } \underline{p}+\Delta \leq p \leq \bar{p}\end{cases}
$$

At prices above the equilibrium support, two cases arise depending on the buyer's demand 
response. If $\bar{p}<V+\Delta / 2$, equivalently $\left.\left(2+\frac{\sqrt{5}}{2}\right) \Delta<V\right)$, then

$$
\begin{aligned}
& \pi(p)= \begin{cases}p-(p-\Delta) F(p-\Delta) & \text { for } \bar{p} \leq p \leq \bar{p}+\Delta \\
\Delta & \text { for } \bar{p}+\Delta \leq p\end{cases} \\
& \text { If } \left.\bar{p}>V+\Delta / 2, \text { equivalently }\left(2+\frac{\sqrt{5}}{2}\right) \Delta>V\right), \text { then } \\
& \pi(p)=\left\{\begin{array}{ll}
\Delta+p[F(2(V+\Delta)-p)-F(p-\Delta)] & \text { for } \bar{p} \leq p \leq \bar{p}+\Delta \\
\Delta & \text { for } \bar{p}+\Delta \leq p
\end{array} .\right.
\end{aligned}
$$

For each $p$, we substitute for the $F$ term as dictated by the distribution specified in the proposition. For any price in the support we readily verify that $\pi(p)=\underline{p}+\Delta \equiv \pi$. For prices below the support, $\pi(p)$ is increasing and continuous in $p$ with the limiting value of $\pi$ as $p \uparrow \underline{p}$. For prices above the support, in each of the two cases, $\pi(p)$ is initially decreasing and continuous in $p$ before collapsing to $\Delta$ at prices above $\bar{p}+\Delta$. In each case, the limiting value is $\pi$ as $p \downarrow \bar{p}$. Thus, the equilibrium is confirmed as all prices in the support yield $\pi$ while all prices outside the support are suboptimal.

Second, we examine the remaining case of $\Delta>\Delta^{*}$. Calculating the profit function, we find

$$
\pi(p)= \begin{cases}p[2-F(p+\Delta)] & \text { for } \bar{p}-\Delta \leq p \leq \bar{p}-2 \Delta \\ p(2-F(p)) & \text { for } \bar{p}-2 \Delta \leq p \leq \bar{p}-\Delta \\ p & \text { for } \bar{p}-\Delta<p \leq \underline{p}+\Delta \\ p-(p-\Delta) F(p-\Delta) & \text { for } \underline{p}+\Delta<p \leq \bar{p} \\ \Delta+(p-\Delta)[F(2 \bar{p}-p)-F(p-\Delta)] & \text { for } \bar{p}<p \leq \bar{p}+\Delta / 2 \\ \Delta & \text { for } \bar{p}+\Delta / 2<p\end{cases}
$$

As before, we substitute for the $F$ distribution specified in the proposition. Verification of the equilibrium then involves a straightforward, but lengthy comparison of payoffs.

Finally, the efficiency property and payoff outcomes were demonstrated in the text.

Inefficient equilibria for large $\Delta$ in the $(2,2)$ capacity configuration. For $\Delta$ sufficiently large, there is a set of inefficient equilibria. Suppose $\Delta>4 V(3-2 \sqrt{2}) \approx .69 \mathrm{~V}$. Then the following distribution $F(p)=(\underline{p}-\Delta) /(2 V+\Delta-p)$ for $p \in[\underline{p}, \bar{p}]$, where $\bar{p}=2(V+\Delta)-\underline{p}$ and $\underline{p} \in(G(\Delta), 2 \Delta)$, where $G(\Delta)=(V-\Delta / 4)^{2} / V+\Delta$, is an equilibrium. The support is a square that is centered on the point $(V+\Delta, V+\Delta)$ and always less than $\Delta$ in width. Referring back to Figure 2 on demand, we see that the buyer either buys a unit from each seller or buys no units in period 1 . Thus, the equilibrium is inefficient. A seller's payoff, $\underline{p}$, is bounded above by $2 \Delta$ which, in turn, is at least 
$\sqrt{V \Delta}$ less than a seller's payoff in the efficient equilibrium.

Proof of Proposition 3. First, we show that $(2,2)$ is not susceptible to entry. Consider a $(2,2,1)$ configuration. In any period 2 subgame every seller has a payoff of 0 . This is because every pattern of period 2 demand purchases results in either an excluded seller or a seller with excess capacity, so that Bertrand logic applies in the subgames. This implies that every seller has a payoff of 0 in the overall game. Suppose 3 units are purchased in period 1. Since the buyer has the option of not buying a 3rd unit in period 1 and instead acquiring that unit next period for a price of 0 , the buyer will not pay a positive price on each unit purchased. Thus, some seller offers a price of 0 and makes a sale. If this is seller $C_{1}$ we are done. If it is one of the $C_{2}$ sellers, then the above argument (for a 3rd unit) holds and the buyer will never pay a positive price. Now suppose 2 units are purchased in period 1. Therefore, some seller has no sales in period 1 and has 0 payoff overall, since there are no profits in period 2. But then no seller can make a sale at a positive price in period 1, since the excluded seller can profitably undercut. Suppose that one unit is purchased in period 1. With two excluded sellers, the previous undercutting argument applies. Finally, if no sales occur in period 1 , then the absence of profits in period 2 implies that all sellers have a payoff of 0 overall. Thus, given a $(2,2)$ configuration, entry is never profitable.

Now, consider the capacity choices of incumbent sellers. We must show that it is not profitable to add or to reduce capacity. Let $\Pi_{i}$ denote the equilibrium profit of seller $C_{i}$ when the capacity configuration is $(2, i)$. It is sufficient to analyze the addition or subtraction of one unit of capacity $(i=1,3)$. This is since $i=0$ automatically has a payoff of 0 and as we note below, choices $i \geq 3$ share a common equilibrium payoff. We will show that $\Pi_{2}>\Pi_{3}$ and $\Pi_{2}>\Pi_{1}$. First, we find $\Pi_{3}$ and compare and then we do the same with $\Pi_{1}$.

Consider $(3,2)$ the buyer has two sellers to choose from and up to 3 units of demand in period 1 , this generates 7 distinct subgames in period 2. Working through all the subgames, the equilibrium payoffs are in Table 1.

Table 2: Discounted Period 2 incremental payoffs for $(3,2)$ capacity game

\begin{tabular}{|c|c|c|c|}
\hline Period $2(B, H, L)$ configuration & Buyer Payoff & Seller $C_{H}$ payoff & Seller $C_{L}$ payoff \\
\hline$(3,3,2)$ & $2(\delta V-\Delta / 3)$ & $\Delta$ & $2 \Delta / 3$ \\
\hline$(2,2,2)$ & $\delta V+\Delta$ & 0 & 0 \\
\hline$(2,3,1)$ & $\delta V-\Delta / 2$ & $\Delta$ & $\Delta / 2$ \\
\hline$(1,2,1)$ & $\Delta$ & 0 & 0 \\
\hline$(1,3,0)$ & 0 & $\Delta$ & 0 \\
\hline
\end{tabular}

All of these reflect pure strategy equilibria except for $(3,3,2)$ and $(2,3,1)$ which are mixed. 
See Figures 5C and 5D.

Moving to period 1, the buyer demand is determined by optimizing over how many units to purchase and from whom given period 2 payoffs and price offers $p_{i}$ and $p_{j}$. See the demand pattern in Figure 6A.

The mixed strategy equilibrium for $(3,2)$ when $\Delta \geq \Delta_{(3,2)}^{*} \equiv\left(\frac{\sqrt{5}-1}{2}\right) V$ is given by

$$
\begin{aligned}
& F_{2}(p)= \begin{cases}1-\left(\pi_{3}-\Delta\right) / p & \text { for } \underline{p}_{2} \leq p \leq \underline{p}_{3} \\
2-\pi_{3} / p & \text { for } \underline{p}_{3} \leq p<\bar{p}_{2} \\
1 & \text { for } p=\bar{p}_{2}\end{cases} \\
& F_{3}(p)= \begin{cases}1-\pi_{2} / p & \text { for } \underline{p}_{3} \leq p<\bar{p}_{2} \\
1-\pi_{2} / \bar{p} & \text { for } \bar{p}_{2} \leq p=\underline{p}_{2}+\Delta \\
2-\pi_{2} /(p-\Delta) & \text { for } \underline{p}_{2}+\Delta \leq p \leq \bar{p}_{3}\end{cases}
\end{aligned}
$$

where $\underline{p}_{2}=\frac{\Delta V}{V+\Delta}, \bar{p}_{2}=V, \underline{p}_{3}=\Delta, \bar{p}_{3}=2 \Delta$. Profit for the $C_{2}$ seller is $\underline{p}_{3}$ and profit for the $C_{2}$ seller is $\underline{p}_{2}+\Delta$. We note that $F_{2}$ has an atom at $\bar{p}_{2}$ and that $F_{3}$ has a flat region. As with the $(2,2)$ configuration, verification of this equilibrium (as well as the 3 subsequent equilibria) involves checking that prices outside of the supports are not profitable relative to the equilibrium payoff. See Figure 6B.

The mixed strategy equilibrium for $(3,2)$ when $\Delta<\Delta_{(3,2)}^{*}$ is given by

$$
\begin{aligned}
& F_{2}(p)= \begin{cases}1-\left(\pi_{3}-\Delta\right) / p & \text { for } \underline{p}_{2} \leq p \leq \underline{p}_{3} \\
2-\pi_{3} / p & \text { for } \underline{p}_{3} \leq p \leq \bar{p}_{2}\end{cases} \\
& F_{3}(p)= \begin{cases}1-\pi_{2} / p & \text { for } \underline{p}_{3} \leq p<\bar{p}_{2} \\
2-\pi_{2} /(p-\Delta) & \text { for } \underline{p}_{2}+\Delta \leq p \leq \bar{p}_{3}\end{cases}
\end{aligned}
$$

where $\underline{p}_{2}=\left(\frac{\sqrt{5}-1}{2}\right) \Delta, \bar{p}_{2}=\left(\frac{\sqrt{5}+1}{2}\right) \Delta, \underline{p}_{3}=\Delta$, and $\bar{p}_{3}=2 \Delta$. Profit for the $C_{2}$ seller is $\underline{p}_{3}$ and profit for the $C_{2}$ seller is $\underline{p}_{2}+\Delta$. See Figure $6 \mathrm{C}$.

To verify that a $C_{2}$ seller has no incentive to add capacity, we compare profit in the $(2,2)$ configuration with the profit of a $C_{3}$ in the $(3,2)$ configuration. It is immediate that $\Delta^{*}<\Delta_{(3,2)}^{*}$. This implies that there are 3 cases to consider when comparing profits. The result then follows immediately by routine calculations. 
Now, consider the $(2,1)$ configuration. The buyer has two sellers to choose from and up to 3 units of demand in period 2. Working through all the subgames, the equilibrium payoffs are in Table 3.

\begin{tabular}{|c|c|c|c|}
\hline \multicolumn{3}{|c|}{ Table 3: Discounted Period 2 incremental payoffs for $(2,1)$ capacity game } \\
\hline Period $2(B, H, L)$ configuration & Buyer Payoff & Seller $C_{H}$ payoff & Seller $C_{L}$ payoff \\
\hline$(3,2,1)$ and $V_{3} \geq V / 2$ & $\delta V-\Delta$ & $2 \Delta$ & $\Delta$ \\
\hline$(3,2,1)$ and $V_{3}<V / 2$ & $\delta V / 2$ & $\delta V$ & $\delta V / 2$ \\
\hline$(2,1,1)$ & $\delta V-\Delta$ & $\Delta$ & $\Delta$ \\
\hline$(2,2,0)$ and $V_{3} \geq V / 2$ & $\delta V-\Delta$ & $2 \Delta$ & 0 \\
\hline$(2,2,0)$ and $V_{3}<V / 2$ & 0 & $\delta V$ & 0 \\
\hline$(1,1,0)$ & 0 & $\Delta$ & 0 \\
\hline
\end{tabular}

All of these reflect pure strategy equilibria except for $(3,2,1)$ when $V_{3}<V / 2$ which is mixed (see Figure 5E).

Moving to period 1, the buyer demand is determined by optimizing over how many units to purchase and from whom given period 2 payoffs and price offers $p_{i}$ and $p_{j}$. Demand can be seen in Figures $7 \mathrm{~A}$ and $7 \mathrm{~B}$ for each of the $V_{3}$ cases.

The mixed strategy equilibrium for $(2,1)$ when $\Delta \geq \Delta_{(2,1)}^{*} \equiv V / 2$ is given by

$$
\begin{aligned}
& F_{1}(p)= \begin{cases}2-\frac{V}{p-\Delta} & \text { for } \underline{p} \leq p \leq \bar{p}\end{cases} \\
& F_{2}(p)= \begin{cases}1-\frac{V}{2(p-\Delta)} & \text { for } \underline{p} \leq p<\bar{p} \\
1 & \text { for } p=\bar{p}\end{cases}
\end{aligned}
$$

where $\underline{p}=\frac{V}{2}+\Delta$, and $\bar{p}=V+\Delta$. We note that there is an atom at $\bar{p}$ for $F_{2}$. The profits for the $C_{1}$ seller are $\underline{p}$ and for the $C_{2}$ seller they are $2 \underline{p}$.

The mixed strategy equilibrium for $(2,1)$ when $\Delta<\Delta_{(2,1)}^{*}$ is given by

$$
\begin{aligned}
& F_{1}(p)= \begin{cases}2-\left(\pi_{2}-2 \Delta\right) /(p-\Delta) & \text { for } \underline{p} \leq p<\bar{p} \\
1 & \text { for } p=\bar{p}\end{cases} \\
& F_{2}(p)= \begin{cases}1-\left(\pi_{1}-\Delta\right) /(p-\Delta) & \text { for } \underline{p} \leq p \leq \bar{p} \\
1 & \text { for } p=V(1+\delta)\end{cases}
\end{aligned}
$$

where $\underline{p}=\frac{V(1+\delta)+\Delta}{2}$, and $\bar{p}=V+\Delta$. The profits are $\underline{p}$ for the $C_{1}$ seller and $2 \underline{p}$ for the $C_{2}$ seller. We observe that there are atoms at the top of both supports and that there is a gap in $F_{2}$ support below $\bar{p}$. It is immediate that $\Delta^{*}>\Delta_{(2,1)}^{*}$. This implies that there are 3 cases to consider when 
comparing profits. The result then follows immediately by routine calculations whenever $\Delta \geq V / 2$. See Figures 7A and 7B for the equilibrium supports.

There is no entry in a $(2,1)$ configuration. If an entrant enters and installs a unit of capacity, then the following is an equilibrium in period 1. Each of the firms who have a unit of capacity charge 0 and the firm with 1 unit of capacity charges $\Delta$, with the buyer buying both units at a price of 0 and the seller with 2 units of capacity selling a unit in period 2 for $V_{3}$. To see that this is an equilibrium, examine seller deviations. If one of the sellers who charges 0 in the putative equilibrium raises its price, then the buyer will buy 1 unit at a price of 0 and one unit at a price of $\Delta$. This gives the buyer a higher payoff than buying units from the seller who deviated, since there will be Bertrand competition between 2 sellers each trying to sell one unit in period 2. Thus, the deviating seller does not benefit. If the seller with 2 units of capacity lowers its price the buyer will buy 1 unit from it and one from one of the sellers charging 0. Again, the price in period 2 will be 0 due to Bertrand competition. Thus, this seller lowers his payoff by lowering its price. Clearly, the seller cannot benefit by raising its price above $\Delta$, since the buyer will still not buy from it in period 1. Thus, we have an equilibrium and entry is not possible. 


\section{References}

[1] Allen, B., R. Deneckere, T. Faith, and D. Kovenock (2000) "Capacity precommitment as a barrier to entry: a Bertrand - Edgeworth approach", Economic Theory, 15, 501-530.

[2] Anton, J.J. and D. Yao (1989) "Split Awards, Procurement and Innovation, RAND Journal of Economics, 20, 538-552.

[3] Anton, J.J. and D. Yao (1992) "Coordination in split award auctions", The Quarterly Journal of Economics, May, 681-707.

[4] Besanko, D. and U. Doraszelski (2004) "Capacity dynamics and endogenous asymmetries in firm size", RAND Journal of Economics, 35(1), 23-49.

[5] Bhaskar V. (2001) "Information and the exercise of countervailing power ", working paper, University of Essex.

[6] Biglaiser, G. and N. Vettas (2004) "Dynamic price competition with capacity constraints and strategic buyers", CEPR discussion paper no. 4315.

[7] Cabral L. M. B. and M. H. Riordan (1994) "The learning curve, market dominance and predatory pricing", Econometrica, 62, 57-76.

[8] Compte O., F. Jenny, and P. Rey (2002) "Capacity constraints, mergers and collusion", European Economic Review, 46, 1-29.

[9] Dasgupta. P. and E. Maskin (1986) "The existence of equilibrium in discontinuous economic games, II: Applications", Review of Economic Studies, LIII, 27-41.

[10] Dobson, P. and M. Waterson (1997) "Countervailing power and consumer prices", Economic Journal, 107, 418-430.

[11] Dudey, M. (1992) "Dynamic Edgeworth-Bertrand competition", Quarterly Journal of Economics, 107(4), 1461-1477.

[12] Dudey, M. (2009) "Quantity pre-commitment and price competition yield Bertrand outcomes", working paper, Rice University.

[13] Garcia, A., J. D. Reitzes and E. Stacchetti (2001) "Strategic Pricing when Electricity is Storable", Journal of Regulatory Economics, 20(3), 223-247. 
[14] Gehrig, T. (1990) Game theoretic models of price discrimination and financial intermediation, Doctoral thesis, London School of Economics.

[15] Ghemawat, P. (1997) Games Businesses Play, Cambridge, MIT Press.

[16] Ghemawat, P. and A.N. McGahan (1998) "Order backlogs and strategic pricing: the case of the U.S. large turbine generator industry", Strategic Management Journal, 19, 255-268.

[17] Greer, W.R. Jr and S.S. Liao (1986) "An analysis of risk and return in the defense market: its impact on weapon system competition", Management Science, 32(10), 1259-1273.

[18] Griesmer, J. and M. Shubik (1963) "Towards a Study of Bidding Processes, Part II: Games with Capacity Limitations," Naval Research Logistics Quarterly, 10, 151-174.

[19] Inderst, R. and C. Wey (2003) "Bargaining, mergers, and technology choice in bilaterally oligopolistic industries", RAND Journal of Economics, 34(1), 1-19.

[20] Inderst, R. (2008) "Single Sourcing and Multiple Sourcing", RAND Journal of Economics, 39(1), 199-213.

[21] Jofre-Bonet, M. and M. Pesendorfer (2003) "Estimation of a dynamic auction game", Econometrica, 71 (5), 1443-1489.

[22] Kreps, D. M. and J. A. Scheinkman (1983) "Quantity precommitment and Bertrand competition yield Cournot outcomes", Bell Journal of Economics, 14(2), 326-337.

[23] Lambson, V.E. (1987) "Optimal penal codes in price-setting supergames with capacity constraints", Review of Economic Studies, 54, 385-397.

[24] Lewis, T. R. and H. Yildirim (2002) "Managing dynamic competition", American Economic Review, 92, 779-797.

[25] Osborne, M. J. and C. Pitchik (1986) "Price competition in a capacity constrained duopoly", Journal of Economic Theory, 38, 238-260.

[26] Riordan, M. H. and D.E.M. Sappington (1987) "Awarding monopoly franchises", American Economic Review, 77, 375-387. 

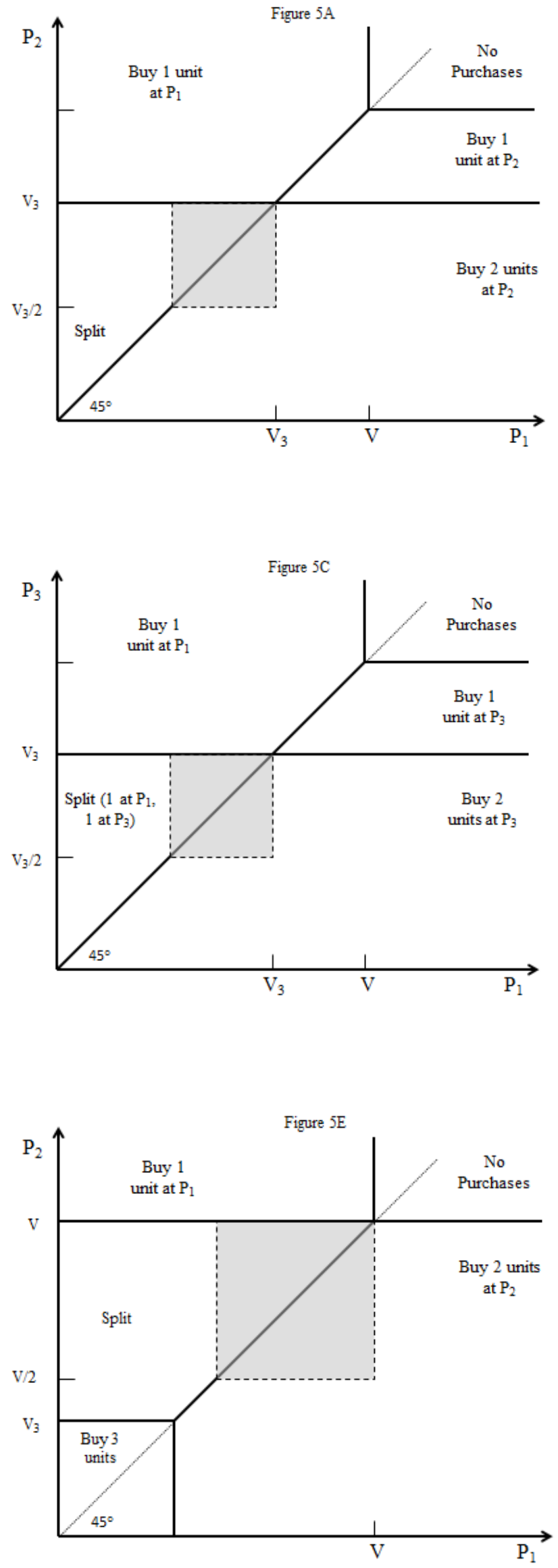
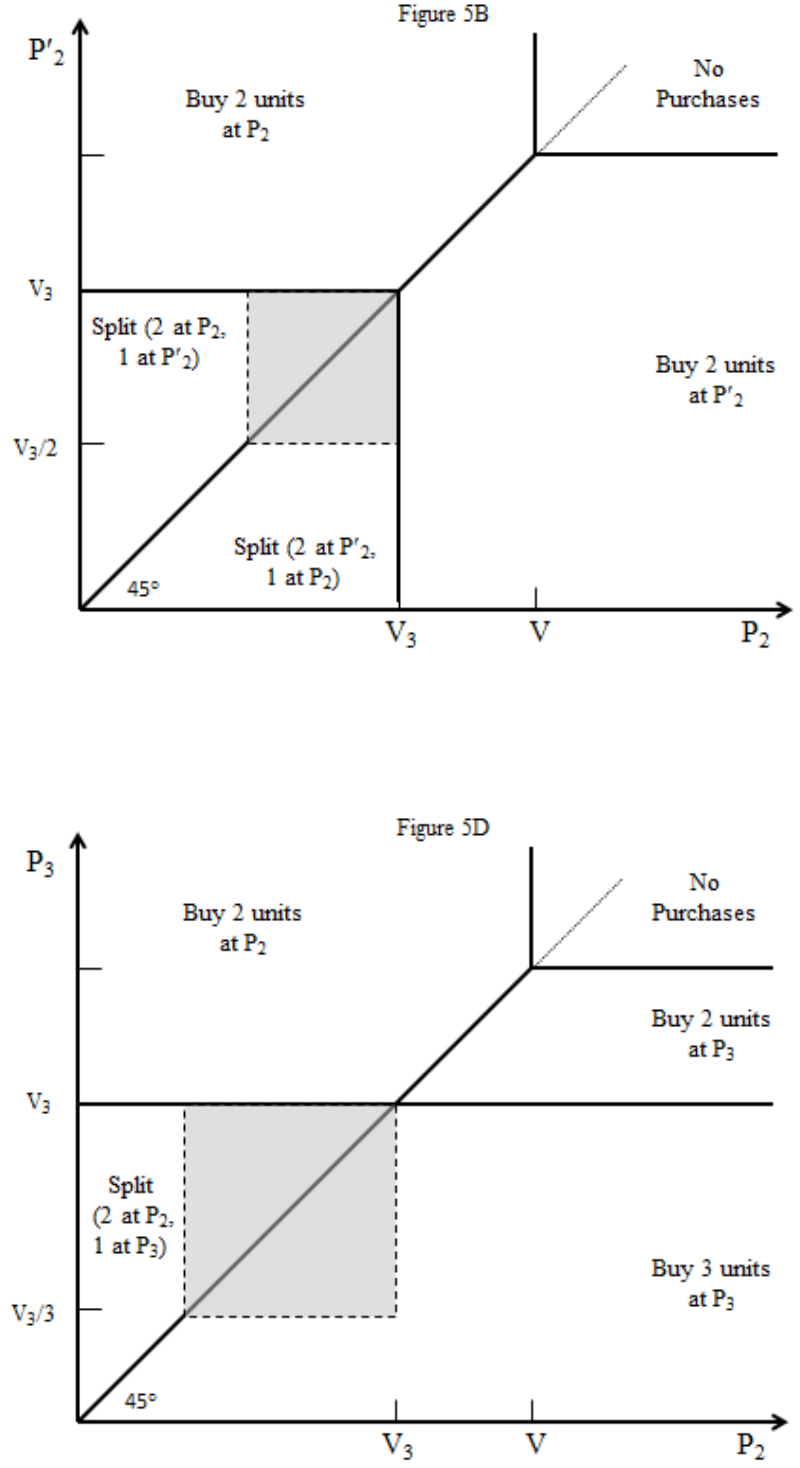

Figure 5: Legend

Capacity $(2,2)$ Subgames:

Figure 5A: $\left(B, C_{H}, C_{L}\right)=(2,2,1)$

Figure 5B: $\left(B, C_{H}, C_{L}\right)=(3,2,2)$

Capacity $(3,2)$ Subgames:

Figure 5C: $\left(B, C_{H}, C_{L}\right)=(2,3,1)$

Figure 5D: $\left(B, C_{H}, C_{L}\right)=(3,3,2)$

Capacity $(2,1)$ subgame:

Figure $5 E$ : $\left(B, C_{H}, C_{L}\right)=(3,2,1)$ 

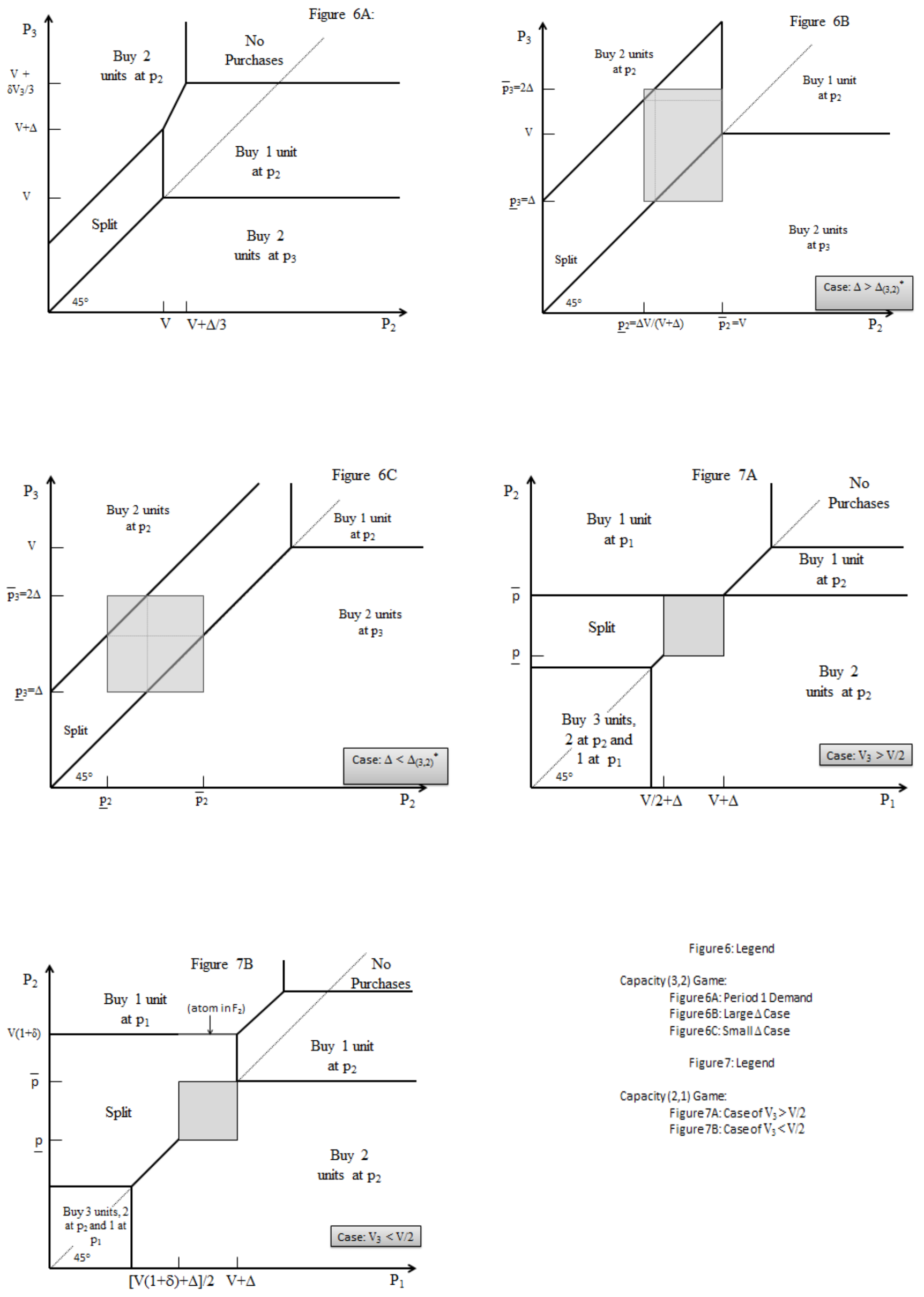

Figure6: Legend

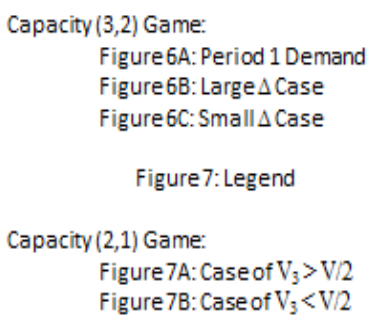

Figure 7A: Case of $\mathrm{V}_{3}>V / 2$

Figure 7B: Case of $\mathrm{V}_{3}<\mathrm{V} / 2$

Buy 2 